\title{
Potensi Kesesuaian Lokasi Wisata Selam Ditinjau dari Aspek Ekologi di Perairan Pantai Pelabuh Dalam Dusun Tuing Kabupaten Bangka
}

\section{The potential suitability of diving tourism locations viewed from ecological aspects in coastal waters pelabuh dalam Tuing Bangka regency}

\author{
Muhammad Fajar ${ }^{1 *}$, Okto Supratman ${ }^{1}$, Indra Ambalika Syari ${ }^{2}$ \\ ${ }^{1}$ Jurusan Manajemen Sumberdaya Perairan FPPB-UBB, Balunijuk \\ ${ }^{2}$ Jurusan Ilmu Kelautan FPPB Universitas Bangka Belitung \\ *Email : majormarley96@gmail.com
}

Diterima Agustus ; disetujui Oktober ; tersedia secara online Oktober

\begin{abstract}
Tuing coastal have potential biological resources of coral reef ecosystem. This potential can be a marine tourism, especially for diving activities. The purpose of this research is to analyze the suitability of dive tourism site in terms of ecological aspects which include biotic \& abiotic parameters, percentage of coral coverage, number of lifeform, reef fish species, visibility, current velocity \& depth of coral reef. This research has carried out in may 2019 at harbour of tuing coastal. Data retrieval refers to yulianda about suitability of dive tourism which consist of the visibility, current velocity, depth of coral reef, percentage coral coverage, lifeform, and reef fish species. Data of suitability parameters have taken at 6 stations. The data has analyzed by scoring method. The result of data show visibility value is $57-100 \%$ current velocity is $1,5-5,6 \mathrm{~cm} / \mathrm{sec}$ and the depth of coral reef is $3-9 \mathrm{~m}$. The result of biotic parameter show percentage coral coverage about 46,6-71,04\%, number of lifeform 5-9 species, and the number of reef fish 8-9 species. The result of calculation The tourism conformity index (IKW) show the location is quite aproriate (S2) for all stations.
\end{abstract}

Keywords: Tuing, Diving Tourism, Suitability

\section{PENDAHULUAN}

Ekosistem terumbu karang memiliki manfaat langsung dan tidak langsung, sebagai salah satu ekosistem utama di kawasan pesisir secara fisik, terumbu karang memiliki peran sebagai pelindung pantai dari hempasan arus dan gelombang. Secara ekologis memiliki peran sebagai habitat bagi berbagai biota laut untuk tempat berlindung, mencari makan, untuk pemijahan (spawning) dan mengasuh (nurseryground )selain itu, dengan keelokan dan keindahannya terumbu karang dapat menjadi salah satu objek daya tarik wisata bahari. Ekowisata bahari merupakan jenis kegiatan pariwisata yang berhubungan dengan kelautan dengan sasaran antara lain melihat/mengamati terumbu karang, berbagai jenis ikan karang, hewan-hewan kecil di laut (microfauna) yang dilakukan dengan cara menyelam, snorkeling, dan berenang (Garrod \& Wilson, 2002).

Perairan Pantai Pelabuh Dalam Tuing terletak di Dusun Tuing Desa Mapur, Kecamatan Riau Silip Kabupaten Bangka. Pantai tersebut memiliki karakteristik yang unik dengan adanya bebatuanbebatuan dan dihiasi pemandangan perbukitan. Perairan Pantai Pelabuh Dalam Tuing memiliki potensi sumberdaya hayati yaitu ekosistem terumbu karang. Perairan Tuing memiliki tipe karang tepi yaitu karang Pelabuh Dalam, karang tengkalet dan karang batu kebo (Aliani, 2018). Hal ini perlunya pengembangan dan pemanfaatan dari potensi yang dimiliki baik dari sumberdaya alam maupun sumberdaya manusia. Terumbu karang dapat dimanfaatkan untuk objek wisata bahari karena memiliki nilai estetika yang sangat tinggi mulai dari warna dan bentuk yang menarik. Pemanfaatan ekosistem terumbu karang di perairan Pantai Pelabuh Dalam Tuing sampai saat ini hanya sebatas tempat mencari ikan bagi nelayan setempat. Hal ini dirasakan kurang maksimalnya dalam memanfaatkan sumber daya alam yang sudah ada.

Potensi terumbu karang di perairan Pantai Pelabuh Dalam Tuing seharusnya mampu menjadi daya tarik bagi wisatawan untuk berkunjung dan mungkin bisa lebih dimanfaatkan seperti menjadi objek wisata bahari khususnya untuk aktifitas selam (diving). Potensi tersebut memungkinkan untuk pengembangan wisata selam namun belum adanya dilakukan pengkajian untuk menunjang aktivitas wisata bahari serta tingkat kesesuaian lokasi di perairan tersebut. Oleh karena itu perlunya dilakukan penelitian di perairan Pantai Pelabuh Dalam Tuing dan penetapan lokasi yang sesuai untuk aktivitas wisata selam. Penentuan lokasi wisata selam perlu dilakukan agar aktivitas wisata selam sesuai pada tempatnya serta tidak merusak lingkungan. Penetapan titik penyelaman dilakukan untuk menjaga wilayahwilayah tertentu agar tidak terganggu oleh kegiatan wisata selam itu sendiri (Adi et al., 2013).

Tujuan penelitian ini adalah mengetahui kesesuaian lokasi untuk wisata selam berdasarkan Yulianda (2007) yang meliputi parameter abiotik dan biotik di perairan Pantai Pelabuh Dalam Dusun Tuing Bangka. 


\section{METODE PENELITIAN}

Penelitian ini dilakukan pada bulan April-Mei 2019 di perairan Pantai Pelabuh Dalam Dusun Tuing kecamatan Riau Silip Kabupaten Bangka. Peta lokasi penelitian disajikan pada Gambar 1.

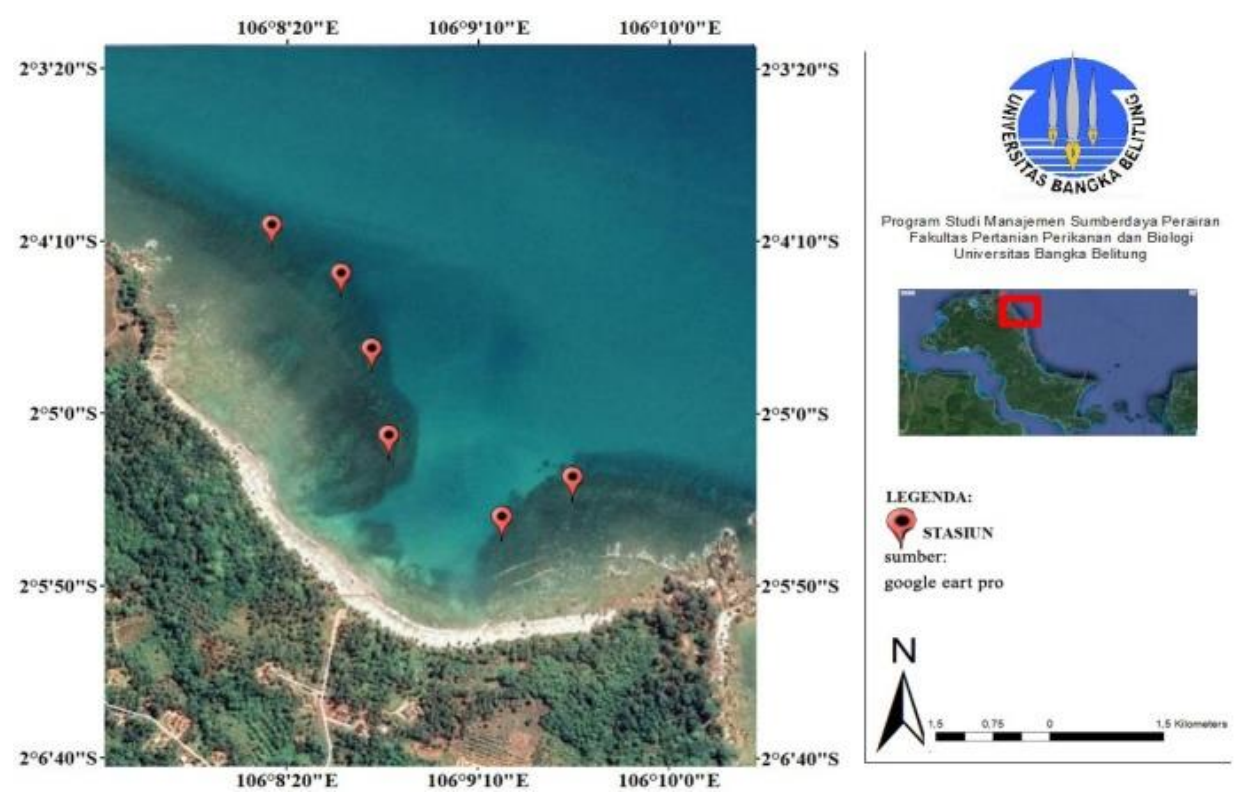

Gambar 1. Lokasi dan Titik Stasiun Penelitian

\section{Alat dan Bahan}

Alat dan bahan yang digunakan dalam penelitian ini meliputi peralatan Selam (SCUBA), Kamera underwater, Roll meter, bola arus dan buku identifikasi terumbu karang dan ikan karang.

\section{Metode Pengambilan Data \\ Dasar Penentuan Stasiun Penelitian}

Penentuan stasiun penelitian yaitu mengunakan metode purposive sampling. Metode purposive sampling adalah metode penentuan stasiun berdasarkan pertimbangan peneliti (Fachrul, 2007). Peneliti mempertimbangkan posisi terumbu karang dari hasil penelitian Aliani (2018) yang menjadi dasar penentuan stasiun dalam penelitian ini. Stasiun penelitian dibagi menjadi enam titik, seluruh titik stasiun mewakili keberadaan terumbu karang yang ada di perairan Pantai Pelabuh Dalam Dusun Tuing. Koordinat masing-masing titik stasiun disajikan pada Tabel 1.

Tabel 1. Koordinat Stasiun Penelitian

\begin{tabular}{ccc}
\hline \multirow{2}{*}{ Stasiun } & \multicolumn{2}{c}{ Koordinat } \\
\cline { 2 - 3 } & $\mathrm{S}$ & $\mathrm{E}$ \\
\hline 1 & $01^{\circ} 35^{\prime} 19.6^{\prime \prime}$ & $106^{\circ} 01^{\prime} 42.2^{\prime \prime}$ \\
2 & $01^{\circ} 35^{\prime} 23.7^{\prime \prime}$ & $106^{\circ} 01^{\prime} 42.3^{\prime \prime}$ \\
3 & $01^{\circ} 35^{\prime} 26.2^{\prime \prime}$ & $106^{\circ} 01^{\prime} 45.1^{\prime \prime}$ \\
4 & $01^{\circ} 35^{\prime} 29.6^{\prime \prime}$ & $106^{\circ} 01^{\prime} 46.7^{\prime \prime}$ \\
5 & $01^{\circ} 35^{\prime} 35.0^{\prime \prime}$ & $106^{\circ} 01^{\prime} 58.7^{\prime \prime}$ \\
6 & $01^{\circ} 35^{\prime} 34.4^{\prime \prime}$ & $106^{\circ} 02^{\prime} 02.7^{\prime \prime}$ \\
\hline
\end{tabular}

\section{Pengukuran Kecerahan Perairan}

Kecerahan perairan diukur dengan mengunakan alat yaitu secchi disk. Kedalaman perairan diukur menggunakan secchi disk dengan cara dicelupkan perlahan-lahan kedalam air hingga mulai tidak terlihat warna hitam dan putih, kemudian diukur kedalamannya (m). Secchi disk diangkat secara perlahan-lahan diamati hingga mulai terlihat warna hitam dan putih, diukur kedalamannya (n). kedalaman perairan diukur $(\mathrm{Z})$ dan dihitung kecerahan (C) dengan menggunakan rumus (Hutagalung et al., 1997) :

$$
C=0,5 \frac{(m+n)}{z} X 100 \%
$$

Keterangan:

$\mathrm{C}:$ Kecerahan $(\%)$

$\mathrm{m}$ : Kedalaman saat batas secchi disc tidak terlihat (m)

$\mathrm{n}$ : Kedalaman saat batas secchi disc mulai terlihat (m)

z : Kedalaman Perairan (m)

\section{Kecepatan Arus}

Kecepatan arus perairan diukur dengan menggunakan bola arus. Pengukuran dilakukan dengan meletakkan bola arus di air yang sebelumnya diikat dengan tali sepanjang satu meter disimbolkan huruf (1). Waktu yang ditempuh untuk rentang satu meter oleh bola arus dicatat sebagai nilai waktu disimbolkan huruf (t) (Hutagalung et al., 1997). Nilai kecepatan arus dihitung menggunakan rumus :

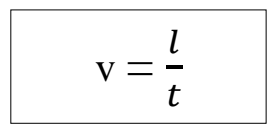

Keterangan :

$\mathrm{v}:$ Kecepatan Arus (m/s)

1 : Panjang (m)

$\mathrm{t}$ : waktu (s) 


\section{Kedalaman Terumbu Karang}

Pengukuran kedalaman terumbu karang dilakukan bersamaan dengan pengambilan data terumbu karang. Pengukuran dilakukan dengan memanfaatkan bagian pengukur kedalaman (depth gauge) pada bagian console regulator selam. Adi et al., (2013) juga melakukan pengukuran kedalaman terumbu karang dengan SCUBA. Pengukuran diawali dengan mengatur jarum pengukur kedalaman (depth gauge) pada posisi nol sebelum penyelaman dilakukan. Pencatatan nilai kedalaman dilakukan pada saat penyelam mencapai dasar perairan.

\section{Tutupan Terumbu Karang}

Terumbu karang diukur dengan menggunakan metode Line Intercept Transect (LIT). Metode ini mengacu pada English et al., (1994) dengan prosedur pengambilan data terumbu karang dengan pemasangan transek garis atau line 50 meter tanpa interval dengan ketelitian transek garis dalam centimeter $(\mathrm{cm})$. Data diambil oleh penyelam dengan merekam video terumbu karang yang berada di line transek garis 50 meter dengan menggunakan kamera underwater dan kemudian data diidentifikasi persentase tutupan (\%) dan jumlah bentuk pertumbuhan (Lifeform) yang ditemukan. Data terumbu karang dihitung dengan menggunakan rumus (English et al., 1994) untuk mendapatkan nilai persentase tutupan. Adapun rumus yang digunakan adalah sebagai berikut:

$$
\mathrm{Ni}=\frac{\mathrm{li}}{\mathrm{L}} \times 100 \%
$$

Keterangan :

$\mathrm{Ni} \quad$ : persen penutupan komunitas karang (\%)

li : panjang total lifeform jenis ke-i $(\mathrm{cm})$

$L \quad$ : panjang transek (m)

Jenis bentuk pertumbuhan terumbu karang dapat ditentukan dengan menghitung langsung berapa banyak jenis bentuk pertumbuhan pada setiap stasiun penelitian.

\section{Pengukuran Data Jumlah Jenis Ikan Karang}

Pengamatan ikan karang menggunakan metode pencacahan langsung (visual sensus) modifikasi dari English et al., (1994). Pengamatan dilakukan pada transek garis yang sama saat pengambilan data persentase tutupan terumbu karang hidup (\%lifecoral) dan jumlah jenis bentuk pertumbuhan terumbu karang (lifeform). Transek garis yang telah dibentangkan sepanjang 50 meter menggunakan peralatan SCUBA dibiarkan kurang lebih 15 menit atau sampai kondisi perairan menjadi seperti semula, dan ikan-ikan yang bersembunyi saat pemasangan transek garis keluar dari persembunyian (Dedi, 2012). Pencatatan data ikan karang dilakukan dengan melihat langsung di stasiun lalu dengan berenang zig-zag dan mencatat sekaligus merekam video di atas transek garis sepanjang $50 \mathrm{~m}$ oleh penyelam. Metode pengambilan data ikan ini dilakukan pada siang hari. Data ikan karang diidentifikasi hingga tingkat jenis (Spesies) dengan acuan buku identifikasi Allen et al., (1999) dan buku identifikasi Kuitler \& Tonozuka (2001).

\section{Analisis Data \\ Skoring dan Pembobotan}

Skoring dan pembobotan dilakukan dengan menghimpun semua data parameter. Pemberian skor pada data parameter berdasarkan nilai parameter tersebut, Sedangkan untuk pembobotan diberikan pada setiap parameter dengan nilai bobot 5,3 dan 1 yang menunjukkan pengaruh parameter tersebut terhadap kesesuaian wisata selam. Semakin besar pengaruh parameter tersebut maka semakin besar pula bobot yang diberikan. Peneliti menambahkan keterangan katagori S1, S2, S3 dan N untuk nilai skor yang diberikan pada setiap parameter. Keterangan Indeks Kesesuaian Wisata (IKW) yang diberikan adalah Sangat Sesuai (S1), Cukup Sesuai (S2), Sesuai Bersyarat (S3) dan Tidak Sesuai (N). Skoring dan pembobotan indeks kesesuaian wisata selam dijabarkan pada Tabel 2.

\section{Analisis Indeks Kesesuaian Wisata (IKW)}

Perhitungan Indeks Kesesuaian Wisata (IKW) mengacu pada rumus Yulianda (2007) sebagai berikut :

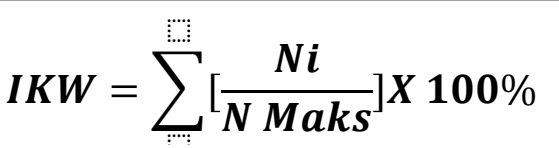

Keterangan :

IKW : Indeks Kesesuaian Wisata

$\mathrm{Ni}$ : Nilai Parameter $\mathrm{Ke}-1$ (bobot x skor)

Nmaks : Nilai maksimum dari suatu kategori wisata

Hasil perhitungan Indeks Kesesuaian Wisata (IKW) dibagi dalam 4 kelas Kesesuaian (Tabel 3):

Tabel 3. Kelas Kesesuaian Wisata Selam

\begin{tabular}{ll}
\hline Kategori & IKW \\
Sangat Sesuai (S1) & $>75-100 \%$ \\
Cukup Sesuai (S2) & $>50-75 \%$ \\
Sesuai Bersyarat (S3) & $>25-50 \%$ \\
Tidak Sesuai (N) & $25 \%$
\end{tabular}

Sumber: Yulianda (2007)

\begin{tabular}{|c|c|c|c|c|c|c|c|c|c|}
\hline Parameter & Bobot & S1 & Skor & $\mathbf{S 2}$ & Skor & $\mathbf{S 3}$ & Skor & $\mathbf{N}$ & Skor \\
\hline Kecerahan (\%) & 5 & $>80$ & 3 & $50 \mathrm{~s} / \mathrm{d} 80$ & 1 & $20 \mathrm{~s} / \mathrm{d}<50$ & 1 & $<20$ & 0 \\
\hline $\begin{array}{l}\text { Tutupan komunitas } \\
\text { karang }(\%)\end{array}$ & 5 & $>75$ & 3 & $>50 \mathrm{~s} / \mathrm{d} 75$ & 1 & $25 \mathrm{~s} / \mathrm{d} 50$ & 1 & $<25$ & 0 \\
\hline Jenis lifeform & 3 & $>12$ & 3 & $<7 \mathrm{~s} / \mathrm{d} 12$ & 1 & $4 \mathrm{~s} / \mathrm{d} 7$ & 1 & $<4$ & 0 \\
\hline
\end{tabular}

Tabel 2. Parameter Kesesuaian Wisata Selam 


\begin{tabular}{|c|c|c|c|c|c|c|c|c|c|}
\hline Parameter & Bobot & S1 & Skor & $\mathbf{S 2}$ & Skor & $\mathbf{S 3}$ & Skor & $\mathbf{N}$ & Skor \\
\hline Jenis ikan karang & 3 & $>100$ & 3 & $50 \mathrm{~s} / \mathrm{d} 100$ & 1 & $20 \mathrm{~s} / \mathrm{d}<50$ & 1 & $<20$ & 0 \\
\hline Kec. Arus $(\mathrm{cm} / \mathrm{sec})$ & 1 & $0 \mathrm{~s} / \mathrm{d} 15$ & 3 & $>15$ s/d 30 & 1 & $>15$ s/d 30 & 1 & $>50$ & 0 \\
\hline $\begin{array}{l}\text { Kedalaman terumbu } \\
\text { karang }(\mathrm{m})\end{array}$ & 1 & $6 \mathrm{~s} / \mathrm{d} 15$ & 3 & $\begin{array}{c}>15 \mathrm{~s} / \mathrm{d} 20 \\
3 \mathrm{~s} / \mathrm{d}<6\end{array}$ & 1 & $>20 \mathrm{~s} / \mathrm{d} 30$ & 1 & $\begin{array}{l}>30 \\
<3\end{array}$ & 0 \\
\hline
\end{tabular}

Sumber : Yulianda (2007)

\section{HASIL DAN PEMBAHASAN}

Hasil

Hasil penelitian kesesuaian lokasi wisata selam di Perairan Pantai Pelabuh Dalam disajikan pada Tabel 4 berikut

Tabel 4. Hasil Nilai Indek Kesesuaian Wisata Selam

\begin{tabular}{|c|c|c|c|c|c|c|c|c|c|c|}
\hline \multirow{2}{*}{ Parameter } & \multirow{2}{*}{ Bobot } & \multicolumn{3}{|c|}{ Stasiun 1} & \multicolumn{3}{|c|}{ Stasiun 2} & \multicolumn{3}{|c|}{ Stasiun 3} \\
\hline & & Hasil & Skor & $\mathbf{N i}$ & Hasil & Skor & $\mathbf{N i}$ & Hasil & Skor & $\mathbf{N i}$ \\
\hline Kecerahan $(\%)$ & 5 & 57.2 & 2 & 10 & 70.5 & 2 & 10 & 64.3 & 2 & 10 \\
\hline $\begin{array}{l}\text { Tutupan terumbu } \\
\text { karang }(\%)\end{array}$ & 5 & 71.04 & 2 & 10 & 53.6 & 2 & 10 & 59 & 2 & 10 \\
\hline $\begin{array}{l}\text { Jumlah jenis } \\
\text { lifeform (buah) }\end{array}$ & 3 & 8 & 2 & 6 & 8 & 2 & 6 & 9 & 2 & 6 \\
\hline $\begin{array}{l}\text { Jumlah jenis ikan } \\
\text { karang (ekor) }\end{array}$ & 3 & 14 & 0 & 0 & 12 & 0 & 0 & 13 & 0 & 0 \\
\hline Arus $(\mathrm{cm} / \mathrm{sec})$ & 1 & 0.033 & 3 & 3 & 0.017 & 3 & 3 & 0.018 & 3 & 3 \\
\hline $\begin{array}{l}\text { Kedalaman } \\
\text { terumbu karang } \\
\text { (m) }\end{array}$ & 1 & 9 & 3 & 3 & 7.8 & 3 & 3 & 7 & 3 & 3 \\
\hline Total Skor & & & & 32 & & & 32 & & & 32 \\
\hline IKW (\%) & & & 59.26 & & & 59.26 & & & 59.26 & \\
\hline Kategori & & & (S2) & & & (S2) & & & (S2) & \\
\hline
\end{tabular}

\begin{tabular}{cccc}
\hline Keterangan & Cukup sesuai & Cukup sesuai & Cukup sesuai \\
\hline Sumber : Hasil Penelitian (2019) & & &
\end{tabular}

\begin{tabular}{|c|c|c|c|c|c|c|c|c|c|c|}
\hline \multirow{2}{*}{ Parameter } & \multirow{2}{*}{ Bobot } & \multicolumn{3}{|c|}{ Stasiun 4} & \multicolumn{3}{|c|}{ Stasiun 5} & \multicolumn{3}{|c|}{ Stasiun 6} \\
\hline & & Hasil & Skor & $\mathbf{N i}$ & Hasil & Skor & $\mathbf{N i}$ & Hasil & Skor & $\mathbf{N i}$ \\
\hline Kecerahan $(\%)$ & 5 & 80 & 2 & 0 & 85 & 3 & 0 & 90 & 3 & 0 \\
\hline $\begin{array}{l}\text { Tutupan terumbu } \\
\text { karang }(\%)\end{array}$ & 5 & 69.6 & 2 & 10 & 50.8 & 2 & 0 & 46.64 & 1 & 5 \\
\hline $\begin{array}{l}\text { Jumlah jenis } \\
\text { lifeform (buah) }\end{array}$ & 3 & 7 & 2 & 6 & 5 & 1 & 3 & 5 & 1 & 3 \\
\hline $\begin{array}{l}\text { Jumlah jenis ikan } \\
\text { karang (ekor) }\end{array}$ & 3 & 11 & 0 & 0 & 8 & 0 & 0 & 9 & 0 & 0 \\
\hline Arus $(\mathrm{cm} / \mathrm{sec})$ & 1 & 0.30 & 3 & 0 & 0.015 & 3 & 0 & 0.056 & 3 & 0 \\
\hline $\begin{array}{l}\text { Kedalaman } \\
\text { terumbu karang } \\
(\mathrm{m})\end{array}$ & 1 & 6 & 3 & 0 & 3 & 2 & 0 & 4 & 2 & 0 \\
\hline Total Skor & & & & 32 & & & 3 & & & 8 \\
\hline IKW (\%) & & \multicolumn{3}{|c|}{59.26} & \multicolumn{3}{|c|}{5.56} & \multicolumn{3}{|c|}{14.81} \\
\hline Kategori & & \multicolumn{3}{|c|}{ (S2) } & \multicolumn{3}{|c|}{ (S2) } & \multicolumn{3}{|c|}{ (S2) } \\
\hline Keterangan & & \multicolumn{3}{|c|}{ Cukup sesuai } & \multicolumn{3}{|c|}{ Cukup sesuai } & \multicolumn{3}{|c|}{ Cukup sesuai } \\
\hline
\end{tabular}


Kesesuaian lokasi wisata selam di perairan Pantai Pelabuh Dalam berdasarkan perhitungan Indeks Kesesuaian Wisata (IKW) menunjukan hasil kategori Cukup Sesuai (S2) pada stasiun 1 dan 6 dengan nilai IKW 51,85\% - 61,11. Hasil perhitungan ditampilkan dalam bentuk Gambar 2.

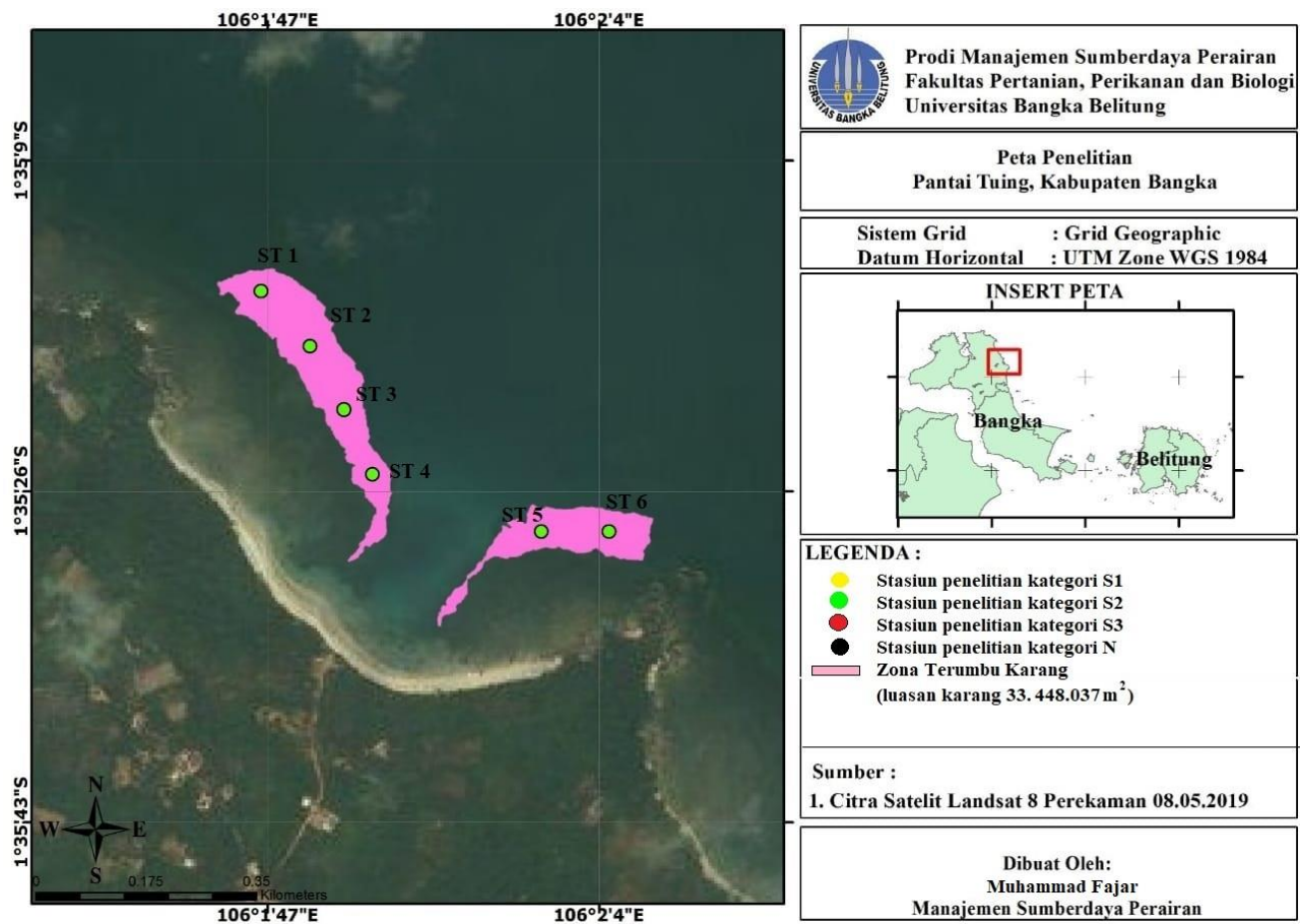

Gambar 2. Peta Indek Kesesuaian Wisata Selam di Perairan Pantai Pelabuh Dalam

\section{Pembahasan \\ Kondisi Parameter Terhadap Daerah Kesesuaian Wisata Selam}

Pengukuran parameter abiotik dan biotik kesesuaian wisata selam dilakukan pada 4 stasiun penelitian. Kondisi perairan pada saat pengambilan data relatif tenang dan cenderung jernih. Perairan pantai ini dipengaruhi oleh dua musim yaitu musim barat dan musim timur, dimana periode musim barat dari bulan September-April dan periode musim timur dari bulan Mei-Agustus. Penelitian ini dilakukan pada awal musim timur yaitu bulan Mei saat kondisi air laut pasang perbani. Hasil peta kesesuaian wisata selam yang disajikan pada Gambar 2. dapat digunakan untuk menunjukan kesesuaian wisata selam pada musim peralihan antara Barat ke timur, tepatnya pada bulan Mei. Lokasi wisata selam yang baik adalah lokasi wisata selam yang memenuhi katagori sesuai terhadap 6 parameter kesesuaiannya. Kecerahan perairan serta keberagaman sumberdaya hayati bawah laut seperti terumbu karang merupakan daya tarik suatu lokasi penyelaman. Adi et al., (2013) menambahkan kondisi lokasi diving yang banyak diminati wisatawan adalah lokasi dengan perairan jernih dan tutupan terumbu karang yang baik.

\section{Parameter Abiotik Kesesuaian Wisata Selam Kecerahan Perairan}

Kecerahan perairan merupakan salah satu parameter Abiotik yang memberikan peranan besar serta memiliki pengaruh dalam menentukan nilai kesesuaian lokasi wisata selam. Kondisi kecerahan di Perairan Pantai Pelabuh Dalam berdasarkan hasil penelitian yang disajikan pada Tabel 5. Hasil penelitian menunjukkan nilai kecerahan Perairan Pantai Pelabuh Dalam masih tergolong baik untuk kegiatan penyelaman. Pada stasiun 1 sebesar $57,2 \%$, stasiun 2 sebesar $70,5 \%$, stasiun 3 sebesar $64,3 \%$, dan stasiun 4 sebesar $80 \%$ yang tergolong dalam kelas cukup sesuai sedangkan stasiun 5 sebesar $100 \%$ dan stasiun 6 sebesar $85 \%$ yang tergolong dalam kelas sangat sesuai (Yulianda, 2007).

Nilai kecerahan terendah terdapat pada stasiun 1 yang terletak di ujung tanjung kayu bulan atau bagian teluk paling luar. Rendahnya nilai kecerahan pada stasiun 1 disebabkan oleh beberapa faktor diantaranya peningkatan kedalaman dan perubahan kecepatan arus yang membawa partikel tersuspensi dari arah utara sehingga menyebabkan air menjadi keruh. Nilai kecerahan tertinggi terdapat pada stasiun 5 sebesar $100 \%$. Tingginya nilai kecerahan stasiun 5 dikarenakan berada di dalam teluk dan kedalaman yang dangkal. Selain itu juga dipengaruhi oleh cuaca lokal pada saat pengambilan data yang berhubungan dengan penetrasi cahaya matahari yang masuk ke kolom perairan. Perairan yang dangkal menyebabkan nilai kecerahan cenderung tinggi dan kondisi air yang jernih, hal ini juga menandakan bahwa Perairan Pantai Pelabuh Dalam masih bagus dan kandungan partikel tersuspensi rendah. Faktor-faktor yang mempengaruhi kecerahan antara lain keadaan cuaca, waktu pengukuran, kekeruhan, serta ketelitian peneliti pada saat pengukuran (Effendi, 2003).

Apriyanto (2016) menyatakan bahwa kecerahan sangat berpengaruh dalam aktivitas penyelaman, hal ini akan mempengaruhi jarak pandang (visibility) seorang penyelam. Philips (2012) menambahkan rendahnya jarak pandang pada saat penyelaman apabila jarak pandang secara horizontal kurang dari satu (1) meter dan 
objek penyelaman seperti terumbu karang akan terlihat jelas jika kecerahan perairan tersebut tinggi. Yulianda (2007) menambahkan kecerahan perairan yang sangat sesuai untuk kegiatan penyelaman berkisar antara $>80$ $100 \%$. Widhianingrum et al., (2013) menambahkan, semakin tinggi tingkat kecerahan semakin baik kondisi serta tingkat keamanan bagi wisatawan yang beraktivitas di perairan tersebut.

\section{Kecepatan Arus}

Kecepatan arus merupakan faktor pembatas dalam kegiatan penyelaman. Kecepatan arus pada Perairan Pantai Pelabuh Dalam berdasarkan hasil penelitian menunjukkan bahwa kecepatan arus perairan tersebut masuk ke dalam kategori sangat sesuai dengan nilai $<15 \mathrm{~cm} / \mathrm{s}$. Yulianda (2007) menyebutkan arus yang baik untuk kegiatan wisata selam berkisar antara $0-<15$ $\mathrm{cm} / \mathrm{s}$. Nilai arus juga dipengaruhi oleh bentuk pantai, keterlindungan perairan, pasang surut serta gelombang. Topografi Pantai Pelabuh Dalam yang membentuk teluk yang diapit oleh dua bukit yaitu bukit Maria Pantai Kayu Bulan dan bukit Tuing sehingga kondisi perairan (Arus dan Gelombang) Pantai Pelabuh Dalam dapat berubah setiap saat. Apriyanto (2016) menyatakan perubahan arus perairan dipengaruhi pasang surut air laut serta gelombang yang disebabkan tiupan angin. Hasil penelitian menunjukkan nilai kecepatan arus dari keenam stasiun berdasarkan pengukuran yang telah dilakukan di lokasi penelitian yaitu $<15 \mathrm{~cm} / \mathrm{s}$ yang masuk dalam kategori sangat sesuai. Secara keseluruhan dari stasiun penelitian menunjukan bahwa Perairan Pantai Pelabuh Dalam memiliki arus yang baik untuk dilakukan aktivitas wisata selam.

Hasil penelitian Apriyanto (2016) mengatakan arus yang kuat akan mempengaruhi pergerakan peselam untuk menjaga keseimbangan dan daya apung (Bouncy). Arus yang kuat juga menganggu kenyamanan dan keamanan dari penyelam itu sendiri. Johan (2016) menyatakan bahwa kecepatan arus yang relatif lemah merupakan syarat ideal untuk wisata bahari kategori selam karena ini berkaitan dengan kenyamanan dan keamanan wisatawan. Kecepatan arus terbaik untuk wisata bahari kategori selam adalah 0-17 cm/s. Penyelaman pada lokasi yang berarus kuat sangat tidak dianjurkan namun, jika terpaksa harus menyelam maka para peselam yang terlibat harus berpengalaman (Philips, 2012). Arus merupakan salah satu parameter penting dalam menentukan kesesuaian suatu kawasan untuk dijadikan kawasan ekowisata bahari kategori wisata snorkeling dan diving, karena untuk snorkeling dan diving membutuhkan perairan yang tenang dan tidak terdapat arus yang bersifat menarik (Nontji. 2007).

\section{Kedalaman Terumbu Karang}

Hasil penelitian menunjukkan kedalaman terumbu karang yang terukur dari keenam titik stasiun penelitian termasuk dalam dua kategori. Stasiun 1, 2, 3, dan 4 yang termasuk dalam kategori sangat sesuai dengan kisaran kedalaman 6-9 meter sedangkan untuk stasiun 5 dan 6 termasuk dalam kategori cukup sesuai dengan kisaran kedalaman 3-5 meter. Yulianda (2007) menyebutkan bahwa kedalaman terumbu karang yang sesuai untuk kegiatan penyelaman berkisar antara 6-15 meter. Kedalaman 6-15 meter menyebabkan tubuh peselam menerima tekanan atmosfir kurang lebih sebesar 2 ATA atau setara dengan 29,4 psi. Tekanan 2 ATA merupakan titik nyaman seorang peselam wisata untuk melakukan kegiatan penyelaman, karena pada umumnya peselam wisata merupakan mereka yang memiliki jenjang sertifikasi A1 (one star).

Widhianingrum et al., (2013) menambahkan bahwa kedalaman perairan untuk wisata diving $<5$ dan $>30$ m dikategorikan tidak sesuai untuk kegiatan diving. Apriyanto (2016) menyebutkan bahwa kedalaman terumbu karang yang kurang dari 3 meter menyebabkan penyelam sulit mengatur keseimbangan atau daya apung (bouyancy) dan juga memungkinkan terjadinya kerusakan pada terumbu karang karena sentuhan fins dan teraduknya sedimen sehingga terumbu karang tertutup lumpur. Kedalaman merupakan parameter yang cukup dipertimbangkan dalam wisata selam karena aktivitas selam memerlukam kedalaman yang cukup dalam agar dapat menunjang mobilitas penyelam dalam kolom air dengan baik dan tidak merusak karang ketika mengamati karang. Zulfikar et al., (2009) menyatakan kedalaman untuk wisata selam memiliki kedalaman lebih dari 3 meter dimana tujuan wisata selam adalah wisatawan dapat melihat keindahan bawah air dari dalam perairan dengan peralatan SCUBA.

\section{Parameter Biotik Kesesuaian Wisata Selam Tutupan Terumbu Karang}

Hasil penelitian tutupan terumbu karang di Perairan Pantai Pelabuh Dalam berkisar antara 46,6$71,04 \%$. Stasiun 1 dengan nilai presentase tutupan sebesar $71,04 \%$, stasiun 2 sebesar $53,6 \%$, stasiun 3 sebesar $59 \%$, stasiun 4 sebesar $69,6 \%$, stasiun 5 sebesar $50,76 \%$, dan untuk stasiun 6 dengan nilai tutupan sebesar 46,6\%. Menurut Yulianda (2007) stasiun 1, 2, 3, 4, dan 5 termasuk dalam kategori cukup sesuai (S2) sedangkan stasiun 6 termasuk dalam kategori sesuai bersyarat (S3). Perbedaan persen tutupan terumbu karang di setiap stasiun penelitian di pengaruhi oleh faktor lingkungan.

Nilai persen tutupan terumbu karang tertinggi terdapat di stasiun 1 yang disebabkan oleh beberapa faktor lingkungan antara lain kecepatan arus dan kedalaman perairan. Arus berfungsi sebagai penyuplai makanan yang diperlukan oleh karang dalam proses pertumbuhan dan suplay oksigen dari laut lepas. Selain itu arus juga berperan dalam proses pembersihan endapan material yang menempel pada polip karang (Giyanto et al., 2017). Kedalaman perairan berkorelasi positif dengan penetrasi cahaya matahari yang masuk ke dalam perairan. Cahaya matahari diperlukan oleh karang untuk proses fotosintesis. Karang sulit tumbuh dan berkembang pada kedalaman dimana penetrasi cahaya sangat kurang biasanya pada kedalaman lebih dari 50 meter (Giyanto et al., 2017). Nilai persen tutupan terumbu karang terendah terdapat di stasiun 6. Stasiun ini berada di bagian terluar teluk yang berdekatan dengan alur kapal nelayan dan daratan. Salah satu penyebab kerusakan terumbu karang yaitu alur pelayaran dan jangkar kapal (Dahuri et al., 2001). Karang yang berdekatan dengan daratan akan langsung terkena pengaruh sedimentasi dari arah daratan dan 
butiran sedimen akan mempercepat penutupan polip karang, bila berlangsung lama bisa menyebabkan kematian karang (Giyanto et al., 2017).

Menurut Yulianda (2007) hasil penelitian menunjukan bahwa persen tutupan terumbu karang di Perairan Pantai Pelabuh Dalam cukup sesuai untuk aktivitas wisata selam. Pengaruh nilai persentase tutupan terumbu karang sangat besar untuk menentukan kesesuaian lokasi wisata selam. Kondisi tutupan karang hidup yang terdapat di Perairan tersebut memiliki potensi cukup besar untuk dikembangkan sebagai objek wisata selam namun disamping itu tak lepas dari pengawasan masyarakat atau pihak pengelola. Hal tersebut untuk memastikan agar tidak ada kerusakan pada terumbu karang yang disebabkan oleh wisatawan/pengunjung yang menyelam. Terumbu karang merupakan salah satu daya tarik diving dimana sebagian besar teru mbu karang tumbuh dengan baik ditemukan pada kedalaman antara 3-10 meter (Thamrin, 2006).

Ekosistem terumbu karang berfungsi sebagai penyedia kesempatan atau peluang untuk rekreasi, dan salah satu manfaat terumbu karang yang berkelanjutan sebagai wisata bahari yaitu wisata yang berorientasi cahaya matahari, laut dan pasir, snorkeling dan selam SCUBA merupakan daya tarik utama di banyak pulau pada daerah tropis (Tomascik et al., 1997). Gadi djou (2013) meyatakan bahwa tutupan terumbu karang dan persentase tutupan terumbu karang merupakan syarat utama dalam pariwisata bahari, karena terdapat unsur utama dari nilai estetika taman laut yang akan dinikmati oleh para wisatawan. Andalan utama kegiatan wisata bahari yang banyak diminati oleh para wisatawan adalah aspek keindahan dan keunikan terumbu karang (Supriharyono, 2007).

\section{Jumlah Jenis Bentuk Pertumbuhan Terumbu Karang}

Bentuk pertumbuhan karang dari enam stasiun penelitian di Perairan Pantai Pelabuh Dalam ditemukan sebanyak 11 jenis yaitu : Acropora Branching, Acropora Digitate, Acropora Tabulate, Acropora Submassive, Coral Encrusting, Coral Foliose, Coral Massive, Coral Mushroom, Coral Submassive, Coral Branching, dan Soft Coral. Bentuk pertumbuhan karang yang sering ditemukan pada setiap stasiun yaitu : Acropora Digitate, Coral Encrusting, Coral Foliose, Coral Massive, dan Coral Submassive. Hasil penelitian menunjukkan terdapat empat stasiun yang jumlah jenis lifeform-nya sama yaitu pada stasiun 1, 2, 5, dan 6. Stasiun 1 ditemukan 8 jenis lifeform, stasiun 2 ditemukan 8 jenis lifeform, stasiun 3 ditemukan 9 jenis lifeform, stasiun 4 ditemukan 7 jenis lifeform, stasiun 5 ditemukan 5 jenis lifeform, dan stasiun 6 ditemukan 5 jenis lifeform.

Hasil penelitian menunjukan bentuk pertumbuhan karang yang ditemukan dari enam stasiun tergolong dalam dua kategori yaitu cukup sesuai dan sesuai bersyarat. Stasiun 1, 2, dan 3 masuk dalam kategori cukup sesuai (S2) dan stasiun 4, 5, dan 6 masuk dalam kategori sesuai bersyarat (S3). Kategori sesuai bersyarat $(25-<50)$ memiliki faktor pembatas yang serius sehingga perlu adanya perlakuan untuk mengurangi pengaruh dari faktor pembatas tersebut (Cahyadinata,
2009). Nilai yang tertinggi terdapat pada stasiun 3 sedangkan nilai yang terendah terdapat pada stasiun 5 dan 6. Dari bentuk pertumbuhan ini menginformasikan bahwa suatu kawasan memiliki faktor pembatas serius (Aprianto, 2016). Bentuk pertumbuhan terumbu karang yang mendominasi dari 6 stasiun penelitian adalah nonacropora yaitu jenis Coral Encrusting, Coral Foliose, Coral Massive, dan Coral Submassive. Siringiringo dan Hadi (2013) dalam Kurniawan et al., (2015) menambahkan bahwa Perairan Pulau Bangka didominasi oleh Coral Massive. Suharsono (2008) menyatakan bentuk-bentuk pertumbuhan terumbu karang terutama Coral Foliose merupakan jenis umum yang ditemukan dan mudah beradaptasi. Apriyanto (2016) menambahkan berdasarkan hasil penelitiannya bahwa karang lembaran (foliose) yang tersusun seperti bunga mawar menambah nilai estestika suatu perairan.

Perairan Pantai Pelabuh Dalam memiliki nilai estetika pada keberagaman bentuk pertumbuhan terumbu karang yang bervariasi dan memberi kesan indah serta kepuasan tersendiri saat berada di bawah air. Keberagaman bentuk pertumbuhan terumbu karang merupakan daya tarik kesesuaian wisata diving yang cukup penting (Apriyanto, 2016). Hal tersebut akan menjadi daya tarik pengunjung maupun penyelam untuk menikmati serta mengamati keindahan dari bentuk pertumbuhan karang itu sendiri. Natha et al., (2014) menjelaskan bahwa dalam wisata bahari jenis lifeform karang dibutuhkan sebagai variasi yang dapat dinikmati di bawah laut, hal ini penting untuk diketahui agar supaya dapat melihat karakteristik dari masing-masing daerah penyelaman karena setiap jenis lifeform memiliki daya tarik yang berbeda.

\section{Jumlah Jenis Ikan Karang}

Hasil pengamatan penelitian menunjukkan jumlah jenis ikan karang yang berbeda-beda pada setiap stasiun. Stasiun 1 terdapat 14 jenis ikan karang, stasiun 2 terdapat 12 jenis ikan karang, stasiun 3 terdapat 13 jenis ikan karang, stasiun 4 terdapat 11 jenis ikan karang, stasiun 5 terdapat 8 jenis ikan karang, stasiun 6 terdapat 9 jenis ikan karang. Jumlah jenis ikan karang yang paling banyak ditemukan pada stasiun 1 yaitu sebanyak 14 jenis ikan karang. Jumlah 14 jenis ikan karang yang yang ditemukan yaitu Abudefduf bengalensis, Casio cuning, Chaetodon octofasciatus, Chelmon rostatus, Halichoeres chrysotaenia, Halichoeres javanicus, Labroides dimidiatus, Lutjanus corponotatus, Neoglyphidodon melas, Neoglyphidodon nigroris, Pomacentrus chrysurus, Pomacentrus fhilipinus, Pomacentrus simsiang, dan Pomacentrus xhantosternus.

Hasil penelitian menunjukkan bahwa jenis ikan karang yang paling sering ditemukan pada setiap stasiun yaitu ikan karang jenis Chaetodon, Neoglyphidodon, dan Pomacentrus. Ikan Pomacentridae merupakan ikan yang mudah ditemukan pada daerah terumbu karang (Kurniawan et al., 2015). Ikan Chaetodon merupakan ikan indikator kesehatan terumbu karang, hal ini sesuai dengan kondisi serta nilai tutupan terumbu karang pada Stasiun 1 sebesar 71,04\% yang masuk dalam Kategori baik menurut Keputusan Menteri Lingkungan Hidup Nomor 4 Tahun (2001). 
Nilai Indeks Kesesuaian Wisata selam (diving) berdasarkan jumlah jenis ikan karang dari keenam stasiun penelitian di Perairan Pantai Pelabuh Dalam termasuk dalam kategori tidak sesuai (N) dengan diberikan skor 0. Kategori tidak sesuai menurut Cahyadinata (2009) merupakan suatu lokasi yang mempunyai parameter pembatas permanen. Nilai tersebut menunjukan bahwa jumlah jenis ikan karang merupakan faktor pembatas dalam menentukan kesesuaian lokasi wisata selam karena jumlah jenis ikan karang memberikan pengaruh yang cukup besar terhadap kesesuaian lokasi untuk kegiatan wisata selam.

Nilai jumlah jenis ikan karang yang tinggi akan meningkatkan nilai kesesuaian lokasi wisata selam (Apriyanto, 2016). Jenis ikan karang yang beragam dan berwarna-warni akan menambah nilai keindahan terumbu karang. Pendapat ini didukung oleh pernyataan Arifin (2008) dalam Rajab et al., (2013) bahwa persentase tutupan komunitas karang, bentuk pertumbuhan terumbu karang, dan jenis ikan karang mempunyai nilai daya tarik bagi wisatawan karena memiliki variasi morfologi dan warna yang menarik.

\section{Kesesuaian Wisata Selam Pantai Pelabuh Dalam}

Kesesuaian wisata selam berdasarkan perhitungan parameter abiotik dan biotik menunjukkan Perairan Pantai Pelabuh Dalam termasuk kedalam satu kategori kesesuaian yaitu kategori cukup sesuai (S2). Kategori cukup sesuai tersebut diberikan pada keenam titik stasiun penelitian dengan nilai Indeks Kesesuaian Wisata Selam (IKW) yang berbeda. Stasiun 1, 2, 3, dan 4 sebesar $59,26 \%$, Stasiun 5 sebesar $61,11 \%$ sedangkan untuk stasiun 6 sebesar $51,85 \%$. Kategori cukup sesuai (S2) menunjukkan bahwa adanya pengaruh dari parameter kesesuaian tersebut. Parameter kesesuaian yang memberikan peranan besar dari keenam stasiun penelitian yakni tutupan terumbu karang, dan kecerahan perairan yakni sesuai dengan tabel skoring dan pembobotan Indeks Kesesuaian Wisata Selam (IKW) Yulianda (2007) dua parameter tersebut memiliki bobot 5 untuk menentukan kesesuaian lokasi wisata selam. Nilai tutupan terumbu karang terendah terdapat pada stasiun 6 yaitu sebesar 46,64\% dengan nilai kecerahan sebesar $85 \%$.

Nilai kecerahan tertinggi terdapat pada stasiun 5 yaitu sebesar $100 \%$ yang masuk dalam kategori sangat sesuai (S1). Berdasarkan tingginya nilai kecerahan tersebut mengindikasikan bahwa daerah tersebut sangat sesuai untuk kegiatan wisata selam, sedangkan nilai kecerahan terendah terdapat pada stasiun 1 yaitu sebesar $57,2 \%$ yang dikategorikan cukup sesuai (S2) untuk kegiatan wisata selam. Nilai tutupan terumbu karang yang tertinggi terdapat pada stasiun 1. Nilai tersebut merupakan nilai tertinggi dari keenam stasiun yang masuk dalam kategori cukup sesuai (S2).Posisi stasiun 1 yang dilindungi oleh bukit menyebabkan terlindung dari arus dan gelombang. Kurniawan et al., (2015) menyatakan tingginya nilai tutupan terumbu karang salah satunya dikarenakan lokasi pengukuran yang terlindung dari arus dan gelombang. Nilai tutupan terumbu karang terendah terdapat pada stasiun 6 yang masuk dalam kategori sesuai bersyarat (S3). Stasiun tersebut berada di bagian terluar pantai atau teluk yang berdekatan dengan alur kapal nelayan dan daratan.

Faktor kesesuaian selanjutnya yang juga memberikan peranan adalah kecepatan arus dan kedalaman terumbu karang. Kecepatan arus dari keenam stasiun tergolong dalam kategori sangat sesuai (S1). Apriyanto (2016) menyatakan kecepatan arus perairan tidak memberikan pengaruh yang besar terhadap penentuan nilai kesesuaian wisata selam. Arifin et al., (2002) dalam Johan et al., (2011) menyatakan bahwa kecepatan arus yang relatif lemah merupakan syarat ideal untuk wisata bahari kategori selam karena ini berkaitan dengan kenyamanan dan keamanan wisatawan, kecepatan arus terbaik untuk wisata bahari kategori selam adalah $0-17 \mathrm{~cm} / \mathrm{s}$. Nilai parameter kedalaman terumbu karang juga termasuk kedalam kesesuaian wisata selam, walaupun nilai kedalaman terumbu karang juga tidak sangat berpengaruh terhadap penentuan kesesuaian lokasi wisata selam namun sangat perlu diperhatikan.

Kedalaman terumbu karang pada stasiun 1, 2, 3, dan 4 masuk dalam kategori sangat sesuai (S1) namun kedalaman terumbu karang bukan merupakan parameter yang memberikan andil besar dalam menentukan kesesuaian lokasi wisata selam (Apriyanto, 2016). Kedalaman terumbu karang yang tidak sesuai untuk aktivitas penyelaman akan beribas pada kerusakan lingkungan (Apriyanto, 2016). Abidin dan Mohamed (2014) dalam Apriyanto (2016) menambahkan kegiatan penyelam yang terlalu dekat dengan terumbu karang secara tidak sengaja peselam mengaduk sedimen sehingga polip karang tertutup dengan sedimen. Barker et al., (2004) dalam Kurniawan et al., (2015) menambahkan bahwa $73,9 \%$ dari 353 penyelam membuat setidaknya sekali kontak terhadap terumbu karang, baik itu karena fins, sentuhan dan pegangan tangan, lutut, dan tendangan.

\section{Pengembangan Wisata Bahari di Pantai Pelabuh Dalam}

Pengembangan serta perintisan Pantai Pelabuhan Dalam untuk sektor wisata dapat dilakukan oleh beberapa kalangan dari masyarakat salah satunya dari kalangan pemuda setempat yang berdomisili di Dusun Tuing, upaya tersebut dapat dilakukan dengan cara bekerjasama dari berbagai pihak pemerintah khususnya dari Dinas Pariwisata dan Kebudayaan Kabupaten Bangka, seperti Pantai Turun Aban dan sekitarnya yang telah menjadi kawasan wisata. Pendekatan dalam melakukan perintisan wisata bahari di Pantai Pelabuh Dalam harus memprioritaskan kelestarian dari pada lingkungan itu sendiri yang tak lain adalah ekosistem serta sumberdaya hayati yang terdapat di perairan tersebut agar terhindar dari hal-hal yang dapat menimbulkan kerusakan fatal. Hal tersebut dapat diupayakan dengan dilandaskan hukum dan peraturan yang jelas serta ketegasan dalam pengawasan yang maksimal, mengingat kawasan Perairan Pantai Pelabuh Dalam akan dijadikan kawasan konservasi maka dari itu perlunya pertimbangan dalam penentuan spot/lokasi bawah air yang sesuai untuk menunjang aktivitas wisata selam (diving). 
Berdasarkan nilai Indeks Kesesuaian Wisata (IKW) selam di Perairan Pantai Pelabuh Dalam Tuing yang menunjukkan bahwa masuk dalam kategori cukup sesuai (S2). Hal tersebut mengindikasikan bahwa potensi bawah air yang dimiliki Perairan Tuing cocok untuk dilakukan aktivitas wisata bahari salah satunya wisata selam, penyelam akan dapat menikmati keindahan terumbu karang mulai dari warna dan bentuk yang menarik, parameter lain yang menunjukkan lokasi tersebut sesuai untuk kegiatan wisata selam yaitu arus yang lambat dan kecerahan perairan yang tinggi karena kondisi perairan yang masih alami dan belum tercemar. Potensi tersebut akan membuat pengunjung/penyelam merasakan kenyamanan serta kepuasan saat menyelam.

Salah satu upaya yang dapat dilakukan dalam merintis aktivitas wisata bahari seperti selam (diving)di Perairan Pantai Pelabuh Dalam yaitu dengan cara menyediakan fasilitas serta akomodasi yang baik kepada wisatawan antara lain: sewa peralatan selam (SCUBA) beserta pemandu/guide yang profesional, pemasangan spanduk atau mempromosikan lewat bebagai media sosial yang berisikan informasi mengenai kegiatan wisata selam yang ramah lingkungan, dan pengadaan penyewaan kapal pengantar penyelam menuju spot/lokasi penyelaman. Pelaksanaan kegiatan wisata bahari tersebut harus disertai pengawasan dengan didampingi pemandu/guide yang professional agar kegiatan tersebut berjalan sesuai dengan prosedur dan dapat meminimalisir kerusakan akibat kegiatan wisata itu sendiri dan keselamatan serta kenyamanan terhadap wisatawan.

\section{SIMPULAN DAN SARAN SIMPULAN}

Simpulan dari hasil penelitian yang telah dilakukan di perairan Pantai Pelabuh Dalam mengenai Potensi Kesesuaian Lokasi Wisata Selam ditinjau dari Aspek Ekologi, menyatakan bahwa Nilai Indeks Kesesuaian Wisata (IKW) untuk wisata selam dari enam stasiun penelitian masuk dalam satu kategori yaitu kategori Cukup Sesuai (S2). Stasiun 1, 2, 3, dan 4 dengan nilai Indeks Kesesuaian Wisata $(59,26 \%)$. Stasiun 5 dengan nilai $(61,11 \%)$ dan stasiun 6 dengan nilai $(51,85 \%)$.

\section{SARAN}

Peneliti menyarankan agar dilakukan penelitian lanjutan mengenai aspek sosial dan ekonomi masyarakat lingkungan Tuing dan Mapur. Peneliti juga mengharapkan adanya penelitian lanjutan yang memperhatikan faktor musim dan pasang-surut dengan menggunakan metode lain seperti metode jelajah dalam pengukuran jenis ikan karang untuk mendapatkan hasil perbandingan kesesuaian lokasi wisata selam.

\section{DAFTAR PUSTAKA}

Abidin SZZ, B Mohamed. 2014. A Review of SCUBA Diving Impacts and Implication for Coral Reefs
Consevation and Turism Management. EDP Sciences. Malaysia.

Adi BA, A Mustafa, R Ketjulan. 2013. Kajian Potensi Kawasan dan Kesesuaian Ekosistem Terumbu Karang di Pulau Lara Untuk Pengembangan Ekowisata Bahari. Jurnal Mina Laut Indonesia. 01(01):1-13

Akbar, A. 2006. Inventarisasi Potensi Ekosistem Terumbu Karang Untuk Wisata Bahari (Snorkeling Dan Selam) Di Pulau Kera, Pulau Lutung Dan Pulau Burung Di Kecamatan Sijuk, Kabupaten Belitung. [Skripsi]. Departemen Manajemen Sumberdaya Perairan. Fakultas Perikanan Dan Ilmu Kelautan. Institut Pertanian Bogor.

Aliani, IP. 2018. Struktur Komunitas Terumbu Karang di Perairan Tuing Kabupaten Bangka. [Skripsi]. Program Studi Manajemen Sumberdaya Perairan. Fakultas Pertanian, Perikanan, dan Biologi. Universitas Bangka Belitung.

Allen, G. R. 1999. Marine Fishes of South-East Asia. Jakarta: Java Books Indonesia.

Ariadno, B., Sitepu, Bi., Khartaharja, S., dan Sutjiadi, RH.2003. Buku Petunjuk 1 Star Scuba Diver CMAS-Indonesia. Jakarta: Dewan Instruktur Selam Indonesia.

Apriyanto, H. 2017. Potensi Kesesuaian Lokasi Wisata Selam Ditinjau Dari Aspek Ekologi Di Perairan Pantai Turun Aban Sungailiat Bangka. [skripsi]. Program Studi Manajemen Sumberdaya Perairan. Fakultas Pertanian, Perikanan, dan Biologi. Universitas Bangka Belitung.

Arifin T, Bengen DG., dan Pariwono. 2002. Evaluasi Kesesuaian Kawasan Pesisir Teluk Palu bagi Pengembangan Pariwisata Bahari. Jurnal Pesisir dan Lautan 4(2):25-35.

Cahyadinata, I. 2009. Kesesuaian Pengembangan Kawasan Pesisir Pulau Enggano untuk Pariwisata dan Perikanan Tangkap. Jurnal AGRISEP 09(02):168- 182.

Dahuri. R, Rais J; Ginting SP; Sitepu. 2001. Pengelolaan Sumber Daya Wilayah Pesisir dan Lautan Secara Terpadu. Jakarta: PT. Pradnya Paramita.

Dedi, 2012. Kelimpahan Ikan Chaetodontidae di Ekosistem Karang di Kawasan Karang Kering Rebo Sungailiat Propinsi Kepulauan Bangka Belitung [Skripsi]. Jurusan Manajemen Sumberdaya Perairan. Fakultas Pertanian, Perikanan dan Biologi, Universitas Bangka Belitung.

Dirawan GD. 2003. Analisis Sosio Ekonomi Dalam Pengembangan Ekotourisme Pada Kawasan Suakamarga Satwa Mampie Lampoko (SocioEconomic Analysis in A Development of Ecoutourism at Mampie Lampoko Reserve). Makalah Falsafah Sains. Program Doktor. 
Sekolah Pascasarjana. Institut Pertanian Bogor. Bogor.

EdICt dan Green Fins. 2009. Panduan Menyelam dan Snorkling Ramah Lingkungan. Kementerian Lingkungan Hidup. Jakarta.

Effendi H. 2003. Telaah Kualitas Air Bagi Pengelolaan Sumberdaya dan Lingkungan Perairan. Yogyakarta: Kanisius.

English, S., Wilkinson, C., dan Baker, V. 1994. Survey Manual For Tropical Marine Resources. Edited by S. English, C.Wilkinson and V.Baker. Australian Institute Of Marine Science. Australia.

Fachrul, M.F. 2007. Metode Sampling Bioekologi. Bumi Aksara. Jakarta.

Gadi Djou, J. A. (2013). Pengembangan 24 Destinasi Wisata Bahari Kabupaten Ende. Jurnal Kawistara 3(1):1-116.

Garrod, B \& J. C. Wilson, 2002. Marine Ecotourism; Issues and Experience. Aspects of Tourism 7. Channel View Publications, Frankfurt Lodge, Clevedon Hall, Victoria Road, Clevedon, BS21 7HH, England.

Giyanto, M. Abrar, Tri Aryono H, Agus B, M. Hafizt, Abdullah S, Marindah Yulia I. 2017. Status Terumbu Karang Indonesia 2017. COREMAPCTI. Pusat Penelitian Oseanografi-LIPI. Jakarta.

Hall CM. 2001. Trends in Ocean and Coastal Tourism: The End of the Last Frontier. Ocean \& Coastal management 44:601-608.

Hutabarat,A. A., Yulianda, F., Fahrudin, A., Harteti, S., Kusharjani. 2009. Pengelolaan Pesisir dan Laut Secara Terpadu. Pusat Pendidikan Dan Latihan Kehutanan-Departemen Kehutanan RI dan SECEM-Korea Internasional Cooperation Agency. Bogor.

Hutagalung, H., D. Setiapermana dan S. Hadi Riyono 1997. Metode Analisi Air Laut Sedimen dan Biota. Jakarta: Pusat Penelitian Pengembangan Oseanografi.

Johan, Y. 2016. Kesesuaian Dan Daya Dukung Ekowisata Bahari Pulau Sebesi Provinsi Lampung. Jurnal Depik 5(2):41-47.

Johan, Y., Yulianda, F., Siregar, V. P., dan Karlina, T. 2011. Pengembangan Wisata Bahari dalam Pengelolaan Sumberdaya Pulau-Pulau Kecil Berbasis Kesesuaian Dan Daya Dukung Studi Kasus Pulau Sebesi Provinsi Lampung. [prosiding] Departemen Pengelolaan Pesisir dan Lautan Sekolah Pascasarjana IPB. Seminar nasional pengembangan pulau - pulau kecil pada tanggal 25 Juni 2011.

Keputusan Menteri Negara Lingkungan Hidup No. 4 Tahun 2001 Tentang: Kreteria Baku Kerusakan Karang.
Kuitler, R. H., dan Tonozuka, T. 2001. Indonesian Reef Fishes (Part 1 dan 2). Zoonetic. Australia.

Kurniawan, F., Destilawaty, Darus, R. F., Dedi, Akmal, S. G., dan Tabunan, J. M. 2015. Potensi Pengembangan Ekowisata Terumbu Karang di Pulau Ketapang, Kabupaten Belitung Timur. [prosiding] Fakultas Perikanan dan Ilmu Kelautan, Universitas Brawijaya. Seminar nasional perikanan dan ilmu kelautan $\mathrm{V}$ tanggal 4 -6 Mei 2015

Natha, H. M., Tuwo, A., dan Samawi, F. 2014. Kesesuaian Ekowisata Selam Dan Snorkling Di Pulau Nusa Ra dan Nusa Deket Berdasarkan Potensi Biofisik Perairan. Jurnal Sains dan Teknologi 14(3):259-268.

Ndruru L. 2009. Kajian Kesesuaian Terumbu Karang Kawasan Pulau Putih Untuk Pengembangan Ekowisata di Kabupaten Tapanuli Tengah. [Tesis]. Bogor: Sekolah Pascasarjana. Institut Pertanian Bogor.

Nontji. A., 2007. Laut Nusantara. Jakarta: Djambatan.

Nyabaken, JW. 1992. Biologi Laut Sebagai Suatu Pendekatan Ekologi. Jakarta: PT. Gramedia.

Orams MB. 1999. Impact and Marine Tourism. Development Management. Published by Routledge. 11 New Fetter Lane. London EC4P 4EE.

Philips M. 2012. Diving Prosedur Manual. University of Queensland. Australia

Rajab, MA. Fachrudin, A. dan Setyobudiandi, I. 2013. Daya dukung perairan Pulau Liukang Loe untuk aktivitas ekowisata bahari. Program Studi Pengelolaan Sumberdaya Pesisir dan Lautan, Fakultas Perikanan dan Ilmu Kelautan IPB/ Jalan Lingkar Kampus IPB Dramaga. Jurnal Depik 2(3):114-125.

Ramadhan, S., P. Patana, Z.A. Harap. 2014. Analisis kesesuaian dan daya dukung kawasan Wisata Pantai Cermin Kabupaten Serdang Bedagai. Makalah. Departemen Manajemen Sumberdaya Perairan. Fakultas Pertanian, Universitas Sumatra Utara, Medan.

Rohmimohtarto, K. dan Juwana S. 2001. Ilmu Pengetahuan Tentang Biologi Laut. Jakarta: Djambatan. 35-48 hlm.

Sodikin, H. 2011. Pertumbuhan Acropora Digitate pada Transplantasi Karang Di Pantai Teluk Limau Sungailiat Provinsi Kepulauan Bangka Belitung. Jurusan Manajemen Sumberdaya Perairan [Skripsi]. Universitas Bangka Belitung.

Suharsono. 2010. Jenis-Jenis Karang Di Perairan Indonesia. Pusat Penelitian Oseanografi LIPI. Jakarta: Coremap Program. 372 hlm.

Supriharyono, 2000. Pengelolaan Ekosistem Terumbu Karang. Jakarta: Djambatan. 12-28 hlm. 
Supriharyono MS. 2007. Konservasi Ekosistem Sumberdaya Hayati di Wilayah Pesisir dan Laut Tropis. Yogyakarta: Pustaka Pelajar.

Tomascik, T., A. J. Mah, A. Nontji \& M. K. Mossa. 1997. The Ecology of the Indonesian Seas. Singapore: Periplus Edition.

Thamrin. 2006. Karang Biologi Reproduksi dan Ekologi. Yogyakarta: Mina Mandiri.

Veron, J.E.N. 2000a. Coral of the world. Vol 1. Australian Insitute of Marine Science, Townsville. 429p.

Veron, J.E.N. 2000b. Coral of the world. Vol 2. Australian Insitute of Marine Science, Townsville. 429p.

Widhianingrum I, Indarjo A, Pratikto I. 2013. Studi Kesesuaian Perairan untuk Ekowisata Diving dan Snorkeling di Perairan Pulau Keramat, Kabupaten Sumbawa Provinsi Nusa Tenggara Barat. Journal Of Marine Research 2(3):181189.

Yulianda, 2007. Ekowisata Bahari Sebagai Alternatif Pemanfaatan Sumberdaya Pesisir Berbasis Konservasi. [prosiding] Departemen Manajemen Sumberdaya Perairan, Fakultas Perikanan dan Ilmu Kelautan IPB. Seminar Sains. Departemen MSP, FPIK IPB, 21 februari 2007.

Yulianda, F., A. Fahrudin, L. Adrianto, A.A. Hutabarat, S. Harteti, Kusharjani dan H.S. Kang. 2010. Kebijakan Konservasi Perairan Laut dan Nilai Valuasi Ekonomi. Pusdiklat Kehutanan Departemen Kehutanan RI dan Secem Korea Internasional Cooperation Agency. Bogor. $113 \mathrm{hlm}$.

Yusri, Safran. 2008. Manfaat Terumbu Karang dan Ancamannya. www.terangi.co.id akses tanggal 2 januari 2013. Jakarta.

Zulfikar, Z, Yusli W, dan I Setyobudiandi. 2009. Kesesuaian dan Daya Dukung Ekosistem Terumbu Karang sebagai Kawasan Wisata Selam dan Snorkling di Tua Pejat Kabupaten Kepulauan Mentawai. Jurnal Ilmu-ilmu perairan dan perikanan Indonesia 17(1):195-203. 